\title{
A educação para as relações étnico-raciais e os estudos sobre racismo no Brasil
}

[ Education for the ethno-racial relations and the studies about racism in Brazil

\author{
Roberto da Silva ${ }^{\mathrm{I}}$
}

\section{Juliano da Silva Tobias ${ }^{2}$}

\begin{abstract}
Texto originado da dissertação de mestrado Negros e negras chegam à universidade: estudo sobre a trajetória acadêmica e as perspectivas profissionais dos cotistas da Unifesp, defendida em 2/9/20I4 no Programa de Pós-Graduação em Educação da Universidade de São Paulo, com apoio da Fundação Ford por meio de bolsa de estudos.
\end{abstract}

RESUMO- Este artigo tem como objetivo fazer a revisão bibliográfica de alguns dos estudos clássicos sobre as relações raciais no Brasil. A revisão engloba o período do início dos anos 30 do século XX até os trabalhos mais recentes, que têm em comum o fato de caracterizarem a discriminação racial como fator importante para a manutenção das desigualdades raciais, reunindo argumentos que fundamentam as reflexões quanto à necessidade da adoção de políticas de ação afirmativa no Brasil, bem como os argumentos que consideram que a pobreza e a desigualdade são os fatores principais que contribuem para a marginalização do negro. Passar a limpo tais teorias e conceitos constitui contribuição significativa para dar efetividade às Diretrizes curriculares nacionais para a educação das relações étnico-raciais e para o ensino de história e cultura afro-brasileira e africana.

\begin{abstract}
- PALAVRAS-CHAVE - Racismo; relações étnico-raciais; educação. · ABSTRACT · The article aims to make a literature review of some of the major studies on race relations in Brazil. The review comprises early $30^{\circ}$ 's ( $20^{\text {th }}$ century) through current one and have in common the fact they regard racial discrimination as an important aspect for the maintenance of racial inequalities, gathering arguments which support the reflections as to the need of the adoption of the affirmative action policies in Brazil, as well as the ones who regards that the poverty and the inequality are the main aspects that contribute to the black people exclusion. Review such theories and concepts makes up a significant contribution to the effectiveness of the National curriculum guidelines for the racial and ethnic relations education. $\cdot$ KEYWORDS · Racism; ethno-racial relations; education.
\end{abstract}

Recebido em 23 de março de 2015

Aprovado em 2 de março de 2016

SILVA, Roberto da; TOBIAS, Juliano da Silva. A educação para as relações étnico-raciais e os estudos sobre racismo no Brasil. Revista do Instituto de Estudos Brasileiros, Brasil, n. 65, p. I77-I99, dez. 2016.

DOI: http://dx.doi.org/Io.II606/issn.23I6-90IX.voi65pI77-I99

I Universidade de São Paulo (USP, São Paulo, SP, Brasil).

2 Universidade de São Paulo (USP, São Paulo, SP, Brasil). 
As Diretrizes curriculares nacionais para a educação das relações étnico-raciais e para o ensino de história e cultura afro-brasileira e africana, instituídas pelo Conselho Nacional de Educação a partir da Resolução n. I, de I7 de junho de 2004, constituem a norma mais atualizada para orientar o tratamento do tema no âmbito da política educacional brasileira.

Da pesquisa de mestrado intitulada Negros e negras chegam à universidade: estudo sobre as trajetórias acadêmicas e as perspectivas profissionais dos cotistas da Unifesp, apresentada ao Programa de Pós-Graduação em Educação da Universidade de São Paulo em 2 de setembro de 20I4, recuperaremos neste artigo a parte de fundamentação teórica que, pensamos nós, pode contribuir de forma objetiva para a formação da "consciência política e histórica da diversidade”, princípio presente nas Diretrizes citadas, que deve conduzir:

[...] - à desconstrução, por meio de questionamentos e análises críticas, objetivando eliminar conceitos, ideias, comportamentos veiculados pela ideologia do branqueamento, pelo mito da democracia racial, que tanto mal fazem a negros e brancos;

- à busca, da parte de pessoas, em particular de professores não familiarizados com a análise das relações étnico-raciais e sociais com o estudo de história e cultura afro-brasileira e africana, de informações e subsídios que lhes permitam formular concepções não baseadas em preconceitos e construir ações respeitosas4.

A formação de educadores e profissionais da área comprometidos com uma educação antirracista não pode prescindir do conhecimento da produção teórica de diversos autores sobre as relações raciais no Brasil. Por meio dele, esses profissionais terão contato com as contribuições, os acertos e os equívocos decorrentes desses trabalhos. Esse fato lhes permitirá questionar algumas ideias

3 BRASIL. Diretrizes curriculares nacionais para a educação das relações étnico-raciais e para o ensino de história e cultura afro-brasileira e africana. Brasília: Ministério da Educação - MEC, 2004, p. I8.

4 Ibidem, p. I9. 
que, embora desacreditadas academicamente, têm grande força no imaginário social e obstaculizam a compreensão mais precisa da realidade racial brasileira.

Na primeira parte deste artigo elencaremos os argumentos extraídos dos estudos sobre desigualdades raciais que apontam a raça como principal fator de precarização da vida da população negra. Na segunda parte abordaremos os argumentos extraídos dos trabalhos que, apesar de admitirem a existência de discriminação racial no Brasil, propõem que a pobreza e a desigualdade sejam os fatores principais que contribuem para a marginalização do negro.

Essa divisão tem como objetivo não só apresentar os argumentos utilizados por muitos pesquisadores e pelo movimento negro em geral no enfrentamento do racismo institucional na educação, mas também fornecer subsídios para enfrentar uma das grandes dificuldades da educação para as relações étnico-raciais, que é a naturalização das relações e a prevalência do mito da democracia racial.

\section{RAÇA COMO PRINCIPAL FATOR DE PRECARIZAÇÃo DA VIDA DA POPUlaÇão NEGRA}

\section{Estudos sobre relações raciais patrocinados pela Unesco (São Paulo e Rio de Janeiro)}

Até meados dos anos I950, o Brasil era visto como um paraíso racial, uma terra onde as relações entre negros e brancos eram harmoniosas e sem nenhum tipo de discriminação entre eles. Essa visão de mundo tomou corpo principalmente no início dos anos I930 com o antropólogo Gilberto Freyre e seus seguidores.

Apoiada nessa visão e chocada com os horrores ocorridos na Segunda Guerra Mundial, causados pelo nazismo e pelo racismo, a Organização das Nações Unidas para a Educação, a Ciência e a Cultura (Unesco) promoveu um conjunto de pesquisas que tinham como objetivo "estudar e coletar materiais científicos relacionados com questões de raça; dar completa difusão para as informações científicas coletadas; preparar uma campanha educacional baseada nessas informações”`.

Contrariando as expectativas da Unesco, que queria usar o Brasil como exemplo de terra livre de preconceito racial, alguns desses trabalhos chegaram a conclusões distintas, dependendo da região do país onde se realizou a pesquisa. Neste primeiro momento, traremos os trabalhos patrocinados pela Unesco que apontaram a discriminação racial como fator de precarização da vida da população negra. $\mathrm{Na}$ segunda parte do artigo, abordaremos aqueles trabalhos patrocinados por ela e que negam ou relativizam o peso da discriminação racial na precarização da vida da população negra na sociedade brasileira.

As pesquisas sobre as relações raciais feitas nos estados mais industrializados do país, como Rio de Janeiro e São Paulo, revelaram realidade distinta da encontrada na Região Nordeste. Para os autores desses trabalhos, a industrialização e a possibilidade

5 MÈTRAUX, Alfred. Unesco and the racial problem. International Social Science Bulletin, v. II, n. 3, I950, p. 384. 
de ascensão social de negros fizeram com que o preconceito racial começasse a se manifestar de modo mais explícito nesses lugares.

A pesquisa que teve como campo de estudo a cidade do Rio de Janeiro, realizada pelo sociólogo Luiz Aguiar Costa Pinto, foi intitulada O negro no Rio de Janeiro: relações de raças numa sociedade em mudança ${ }^{6}$.

Nesse trabalho, Luiz Costa Pinto nos conta que, na época da escravidão, brancos e negros ocupavam, respectivamente, os postos de senhores e escravos. Por essas posições sociais estarem bem marcadas na sociedade escravocrata, o preconceito racial, como mecanismo de defesa de posições, não tinha razão de existir.

A ascensão social dos negros, provocada pela industrialização no Rio de Janeiro, e a formação de uma sociedade de classes sociais abertas fizeram com que o preconceito, de acordo com o autor, se transformasse em instrumento para manter a precarização da vida da população negra, gerando assim a discriminação racial que a vitima.

Dentro desse quadro:

[...] o preconceito e a discriminação atuam fundamentalmente no sentido de reconduzir ao seu lugar o negro que historicamente sai desse lugar, o lugar que tradicionalmente ocupava no sistema de relações sociais, lugar que a ideologia do grupo socialmente dirigente e etnicamente diferenciado considera próprio, natural, biologicamente justificado - tão próprio, natural e biologicamente justificado quanto o seu de grupo dominante?.

Já a pesquisa que teve como campo de estudo a sociedade paulistana foi realizada pelos sociólogos Roger Bastide e Florestan Fernandes ${ }^{8}$ e gerou o livro Brancos e negros em São Paulo: ensaio sociológico sobre aspectos da formação, manifestações atuais e efeitos do preconceito de cor na sociedade brasileira. Nesse trabalho, os autores nos ensinam que a transição da sociedade escravocrata para a sociedade de classes não foi capaz de promover mudanças significativas que desorganizassem o sistema de relações sociais característico da escravidão. Com isso, não foi possível fazer com que cor deixasse de ser vista como símbolo de posição social e referência com o poder de gerar expectativas de comportamento ou de promoção de direitos e deveres recíprocos nas relações sociais.

Além da persistência dessas expectativas e de um comportamento negativo em relação ao negro, Bastide nos mostra que há uma negação no Brasil da existência de preconceito em relação ao negro:

6 PINTO, Luiz Aguiar Costa. O negro no Rio de Janeiro: relações de raças numa sociedade em mudança. São Paulo: Companhia Editora Nacional, I953, p. 3I8.

7 Ibidem, p. 318.

8 FERNANDES, Florestan. Cor e estrutura social em mudança. In: BASTIDE, Roger \& FERNANDES, Florestan. Brancos e negros em São Paulo: ensaio sociológico sobre aspectos da formação, manifestações atuais e efeitos do preconceito de cor na sociedade brasileira. São Paulo: Global, 2008, p. 9I-I54. 
"Nós brasileiros", dizia-nos um branco, "temos o preconceito de não ter preconceito. E esse simples fato basta para mostrar a que ponto está arraigado no nosso meio social”. Muitas respostas negativas explicam-se por esse preconceito de ausência de preconceito, por essa fidelidade do Brasil ao seu ideal de democracia racial. [...] É verdade que esse ideal de democracia impede as manifestações demasiado brutais, disfarça a raça sob a classe, limita os perigos de um conflito aberto. Se a isso acrescentarmos certa bondade natural do brasileiro, o hábito adquirido há séculos de viver com os negros e, mesmo, por vezes, uma certa displicência, compreenderemos melhor que o preconceito não se exprima abertamente, mas de um modo sutil ou encoberto?

Embora Fernandes ${ }^{\text {Io }}$ aponte a persistência do passado, que se consubstanciaria por meio de uma representação negativa da personalidade e do status do negro, que dificultaria sua ascensão social, ele acreditava que se tratava de fenômeno transitório. Para defender sua tese, apoia-se na ideia de que a sociedade paulista sempre se orientou no sentido de fazer prevalecer os princípios de integração estrutural sobre as diferenças raciais, étnicas e culturais. Para o autor, se essa tendência se perpetuasse dentro do regime de trabalho livre e de dominação capitalista, a antiga correspondência entre cor e posição social perderia significado e ponto de apoio estrutural. Com isso, ocorreria um processo de incorporação dos negros às classes sociais, que produziria efeitos que refletiriam diretamente na própria constituição do sistema de relações raciais. Ou seja, a discriminação racial era vista como prática social característica da ordem escravocrata, que desapareceria com a consolidação da sociedade de classes capitalista.

Opinião semelhante a essa tem Luiz Aguiar Costa Pinto ${ }^{\text {II }}$ ao dizer que, mesmo dentro do sistema de estratificação e de valores da época, havia uma lenta ascensão social de negros. Todavia, o autor pondera que, dentro das dificuldades que a situação encerra, é possível a ascensão de uma elite negra, mas a de uma massa de negros na sociedade brasileira somente ocorreria no âmbito da ascensão social da massa de brasileiros, das quais os negros fazem parte. Vale a pena ressaltar que essa ideia foi bastante criticada pelo movimento negro da época, que não acreditava que somente a consolidação da sociedade de classes seria suficiente para acabar com preconceitos e discriminações.

Outro trabalho que até hoje serve de referência nos estudos sobre relações raciais foi realizado pelo sociólogo Oracy Nogueira ${ }^{\mathrm{I2}}$, chamado "Preconceito racial de marca e preconceito racial de origem (sugestão de um quadro de referência para a interpretação do material sobre relações raciais no Brasil)”.

9 BASTIDE, Roger. Manifestações do preconceito de cor. In: BASTIDE, Roger \& FERNANDES, Florestan. Brancos e negros em São Paulo: ensaio sociológico sobre aspectos da formação, manifestações atuais e efeitos do preconceito de cor na sociedade brasileira. São Paulo: Global, 2008, p. I55.

Io FERNANDES, Florestan, 2008, op. cit.

II PINTO, Luiz Aguiar Costa, op. cit.

I2 NOGUEIRA, Oracy. Preconceito racial de marca e preconceito racial de origem (sugestão de um quadro de referência para a interpretação do material sobre relações raciais no Brasil). In: Tanto preto quanto branco: estudos de relações raciais. São Paulo: T. A. Queiroz Editor, I985, p. 67-93. 
Ao fazer nesse estudo uma reflexão sobre os trabalhos patrocinados pela Unesco, Nogueira ${ }^{\text {I3 }}$ diz que, ao contrário do que ocorria anteriormente, houve um explícito reconhecimento da existência de preconceito racial no Brasil. Porém, o autor pondera que essa constatação não seria suficiente se ignorássemos as diferenças entre o tipo de relações entre negros e brancos no Brasil e nos Estados Unidos. Com isso, ele questiona se as relações raciais nesses dois países diferem em intensidade ou se há uma diferença qualitativa.

Partindo dessa constatação, Nogueiraa ${ }^{\mathrm{I} 4}$ elabora sua reflexão dentro do âmbito restrito do preconceito racial, desdobrando-o em dois tipos: quando o preconceito se exerce em relação à aparência, aos gestos, ao sotaque, o autor diz que esse tipo é de marca, que seria o predominante no Brasil; quando o preconceito se exerce pelo fato de um indivíduo ser descendente de certo grupo étnico ou racial, afirma que é de origem, que seria o tipo de preconceito dominante nos Estados Unidos. Isso faz com que o tipo de preconceito vigente em uma dada sociedade determine o modo como se dão as relações entre os diversos grupos étnicos e raciais.

Nos lugares onde o preconceito é de marca, a probabilidade de ascensão social está relacionada, de acordo com Nogueira ${ }^{\mathrm{IS}}$, com a intensidade e a quantidade de marcas fenotípicas que o indivíduo venha a possuir, fazendo com que o preconceito racial fique disfarçado sob o preconceito de classe, com o qual tende a coincidir. Ou seja, a maior presença ou a ausência de traços fenotípicos negros podem determinar maior dificuldade ou não na ascensão social dos indivíduos.

Nos lugares onde vige o preconceito de origem, Nogueira ${ }^{\text {T6 }}$ diz que os grupos discriminadores e discriminados permanecem rigidamente separados, como se fossem duas sociedades totalmente distintas, e não se confundem. Os estudos patrocinados pela Unesco que se detiveram na análise das relações raciais nas regiões mais industrializadas do país, ao invés de confirmarem a visão até então mundialmente conhecida de que o Brasil é um país onde não há discriminação racial, mostraram exatamente o contrário: o racismo e a discriminação racial são fenômenos presentes na sociedade brasileira, e a cor, ao contrário do senso comum da época, é critério que fundamenta o tratamento desigual entre negros e brancos.

Esses trabalhos foram extremamente importantes porque questionaram a visão então hegemônica de que o Brasil seria uma sociedade livre de discriminação racial. A partir deles, começaram a surgir outras investigações que foram desdobramentos desses trabalhos iniciais. Dentre esses, podemos citar os produzidos pela Escola Paulista de Sociologia, que deu prosseguimento aos estudos sobre discriminação racial no Brasil, agora questionando a visão de que a escravidão no Brasil foi mais benévola que em outros países, e de que o país seria uma democracia racial em que negros e brancos seriam tratados da mesma maneira.

I3 Ibidem

I4 Ibidem.

I5 Ibidem.

I6 Ibidem. 


\section{A Escola Paulista de Sociologia e o mito da democracia racial}

O historiador Richard Graham ${ }^{\mathrm{I7}}$ destaca, no texto "Brazilian slavery re-examined: a review article", que a visão de uma escravidão suave e de senhores benevolentes e escravos leais acabou prevalecendo na literatura e na história. Esses foram, de acordo com o autor, um dos mitos forjados por uma sociedade cujo objetivo era defender um sistema que considerava ideal.

Questionando essas ideias, surgiram novas investigações que abordaram a história da escravidão no Brasil e o período de transição de uma sociedade escravocrata para uma sociedade livre. Segundo $\mathrm{Graham}^{\mathrm{I}}$, o centro de produção dessas novas pesquisas foi a Universidade de São Paulo (USP). O grupo de pesquisa constituído ficou conhecido como Escola Paulista de Sociologia.

O autor destaca que o sociólogo Florestan Fernandes organizou sua própria cadeira de pós-graduação, em que foram realizados grandes estudos sobre relações raciais em várias áreas, com especial atenção aos aspectos históricos.

Dentre as pesquisas originárias desse grupo estão os trabalhos produzidos pelos orientandos de doutorado de Florestan Fernandes, os sociólogos Octavio Ianni e Fernando Henrique Cardoso, e a sua própria pesquisa, elaborada para o concurso de professor titular para a cadeira de Sociologia I da USP.

Ao analisar a transição do sistema escravista para o sistema de trabalho livre, Octavio Ianni ${ }^{\text {I9 }}$, no livro As metamorfoses do escravo: apogeu e crise da escravatura no Brasil Meridional, que estudou a escravidão no Paraná, aponta que as mudanças na estrutura econômica escravista não acompanharam, no mesmo ritmo, as mudanças na estrutura social.

Nessa transição, brancos e negros transportaram consigo valores, padrões, ideais, técnicas de comportamentos específicos do mundo escravista, que convergiam com a identificação do negro como membro da camada inferior ${ }^{20}$.

Com a persistência desse conjunto de valores sobre a cor, Ianni ${ }^{2 \mathrm{I}}$ afirma que o senhor e o escravo se metamorfosearam, respectivamente, em branco, e em negro e mulato, porque o mundo que criou tanto o senhor como o escravo, de certa maneira, persistiu na sociedade livre, com esses personagens se prolongando também nas pessoas.

Isso fez com que a discriminação se transformasse em um meio de manutenção da distância social que foi originada no sistema escravista e da própria ideia de negro e branco que foi gerada nesse mesmo sistema de produção ${ }^{22}$.

I7 GRAHAM, Richard. Brazilian slavery re-examined: a review article. Journal of social history, v. 3, n. 4, Summer, I970, p. 43I-453.

I8 Ibidem.

I9 IANNI, Octavio. O negro e o mulato. In: . As metamorfoses do escravo: apogeu e crise da escravatura no

Brasil Meridional. São Paulo: Difusão Europeia do Livro, I962, p. 236-268.

20 Ibidem.

2I Ibidem.

22 Ibidem. 
Já Fernando Henrique Cardoso ${ }^{23}$, no livro Capitalismo e escravidão no Brasil meridional: o negro na sociedade escravocrata do Rio Grande do Sul, nos mostra que, após a abolição da escravatura, o negro livre passou a ameaçar de modo mais amplo as expectativas dos brancos e a exclusividade das posições mantidas por eles, originárias do período escravocrata.

De acordo com Cardoso 24 , a sociedade de classes, que se caracteriza pela igualdade jurídica de todos os cidadãos, fez com que surgisse a necessidade de se desenvolver mecanismos sociais que garantissem, em nome de uma desigualdade natural, a acomodação dos negros ao sistema de atribuição de posições e vantagens assimétricas. Esses mecanismos garantiriam um suprimento abundante de mão de obra, além da perpetuidade no usufruto de posições de autoridade e de prestígio que a ordem escravista assegurava aos brancos e aos senhores.

Sendo assim, o preconceito muda de conteúdo e de funções sociais:

Com a desagregação da ordem servil, que naturalmente antecedeu, como processo, à abolição, foi-se constituindo, pouco a pouco, o problema negro, e com ele intensificandose o preconceito com novo conteúdo. Nesse processo, o "preconceito de cor ou de raça" transparece nitidamente na qualidade de representação social que toma arbitrariamente a cor ou outros atributos raciais distinguíveis, reais ou imaginários, como fonte para a seleção de qualidades estereotipáveis. De um momento para outro, o negro - que fora sustentáculo exclusivo do trabalho na escravidão - passa a ser representado como ocioso, por ser negro, e assim por diante ${ }^{25}$.

$\mathrm{Na}$ esteira da produção científica da Escola Paulista de Sociologia, Florestan Fernandes ${ }^{26}$ mostra, no estudo clássico A integração do negro na sociedade de classes, que, no desejo de prevenir supostas tensões raciais que poderiam surgir no pós-abolição e assegurar um meio eficaz de integração social dos negros na sociedade, fecharam-se todas as portas que poderiam colocar os negros na área dos benefícios diretos do processo de democratização dos direitos e garantias sociais.

Esse tipo de relação originou, segundo Fernandes ${ }^{27}$, um fruto espúrio, a saber, o mito da democracia racial. Para o autor, esse mito, criado pelas elites dominantes, teria uma utilidade prática ao generalizar um estado de espírito que permitia atribuir à incapacidade ou à irresponsabilidade do próprio negro as dificuldades vividas por ele. Segundo Fernandes, isso isentaria o branco de qualquer obrigação, responsabilidade ou solidariedade moral perante os efeitos da espoliação abolicionista e da deterioração progressiva da situação socioeconômica do negro e do mulato.

23 CARDOSO, Fernando Henrique. Capitalismo e escravidão no Brasil meridional: o negro na sociedade escravocrata do Rio Grande do Sul. Rio de Janeiro: Civilização Brasileira, 2003.

24 Ibidem, p. 2 I3.

25 Ibidem.

26 FERNANDES, Florestan. Heteronomia racial na sociedade de classes. In: A integração do negro na sociedade de classes. Volume I - O legado da "raça branca”. São Paulo: Cia. Editora Nacional, I965, p. I9I-26I. 27 Ibidem. 
O mito também revitalizou a ideia de avaliar as relações raciais pela aparente ausência de conflitos raciais, gerando uma falsa consciência (impressão) da realidade racial brasileira. Para o autor, isso levou as pessoas a pensarem que não existem distinções raciais no Brasil, que há igualdade de oportunidades para todos e que os problemas dos negros são residuais e transitórios, podendo ser tratados e superados pelos meios tradicionais e por mudanças qualitativas espontâneas ${ }^{28}$. Os estudos sobre a escravidão e a transição da sociedade escravocrata para a sociedade de trabalho livre no Brasil questionaram o senso comum até então vigente de que a escravidão foi mais cordial no Brasil do que em outros países. Além disso, mostraram que os preconceitos e as discriminações que os negros sofriam na época do cativeiro não foram extintos nessa época, continuando mesmo após a abolição da escravatura. Nessa época, esses preconceitos deixaram de ser fundamentados pela religião e passaram a ser fundamentados pelas ciências biológicas e antropológicas da época. A tese do branqueamento

[...] baseava-se na presunção da superioridade branca, às vezes, pelo uso dos eufemismos raças "mais adiantadas" e "menos adiantadas" e pelo fato de ficar em aberto a questão de ser a inferioridade inata. À suposição inicial, juntavam-se mais duas. Primeiro - a população negra diminuía progressivamente em relação à branca por motivos que incluíam a suposta taxa de natalidade mais baixa, a maior incidência de doenças e a desorganização social. Segundo - a miscigenação produzia "naturalmente" uma população mais clara, em parte porque o gene branco era mais forte e em parte porque as pessoas procuravam parceiros mais claros do que elas (a imigração branca reforçaria a resultante predominância branca) ${ }^{29}$.

Com o tempo, essas teses sobre a superioridade biológica dos brancos passaram a ser desacreditadas por trabalhos posteriores, que defendiam a unidade da espécie humana e rechaçavam qualquer tipo de hierarquização entre os diversos grupos humanos. Contudo, essas teorias não ficaram confinadas ao mundo acadêmico: transformaram-se em políticas públicas e acabaram contaminando o tecido social, moldando comportamentos e reforçando preconceitos.

Na sociedade de classes, o preconceito racial tinha como função a manutenção da distância entre negros e brancos.

Além disso, a ideia de que o Brasil seria uma democracia racial foi questionada, transformando-se então em um mito, em uma falsa ideologia, que serviria tão somente para aplacar os anseios reivindicatórios dos negros, responsabilizando-os pelo estado de precarização da população negra e isentando a sociedade nacional de qualquer inclinação racista.

Os estudos realizados por Carlos Hasenbalg e Nelson do Valle Silva ${ }^{30}$ questionaram

28 Ibidem.

29 SKIDMORE, Thomas E. Preto no branco: raça e nacionalidade no pensamento brasileiro. Rio de Janeiro: Paz e Terra, I989, p. 8I.

30 VALLE SILVA, Nelson do. Diferenças raciais de rendimentos. In: HASENBALG, Carlos; VALLE SILVA, Nelson do; LIMA, Márcia. Cor e estratificação social. Rio de Janeiro: Contra Capa, I999, p. I84-2I6. 
a visão, até então defendida por alguns sociólogos, de que a industrialização e a consolidação da sociedade de classes eliminariam a discriminação racial na sociedade brasileira. Esses estudos mostraram que a discriminação não era algo que pertencia a uma ordem social anterior, mas que ainda operava na sociedade atual como mecanismo de seleção e manutenção dos postos sociais mais valorizados nas mãos dos brancos.

\section{Os estudos de Carlos Hasenbalg e Nelson do Valle Silva sobre discriminação racial}

Os estudos sobre as relações raciais no Brasil sofrem uma mudança paradigmática importante com a publicação do livro do sociólogo argentino Carlos Hasenbalg3', Discriminação e desigualdades raciais no Brasil, originalmente uma tese de doutoramento apresentada na Universidade da Califórnia, nos Estados Unidos.

Nesse trabalho, Hasenbalg detectou que a industrialização, longe de extinguir a ordem racial preexistente, acabou reproduzindo internamente a estrutura mais ampla de supraordenação e subordinação da sociedade global.

Com isso, o autor afirma que a raça, como traço fenotípico historicamente elaborado, é um dos critérios mais importantes que influenciam a seleção para a ocupação de posições na sociedade. Para ele, a persistência histórica da discriminação racial não deve ser entendida como um simples legado do passado, mas como ferramenta que serve aos complexos e diversificados interesses do grupo racialmente dominante.

Para Hasenbalg a evidência empírica indica que os negros estão expostos a um ciclo de desvantagens em termos de mobilidade social. De acordo com o autor, nascer negro ou mulato no Brasil significa nascer em famílias de baixo status econômico, e as probabilidades de ascender socialmente são consideravelmente menores para os negros do que para os brancos da mesma origem social. Além disso, ele mostra que os negros sofrem com uma desvantagem competitiva em todas as fases do processo de transmissão de status social e econômico.

O sociólogo Nelson do Valle Silva ${ }^{32}$ também escreveu diversos trabalhos sobre mobilidade social e efeitos da discriminação racial sobre os negros. Em um artigo escrito para o livro Cor e estratificação social, ele considera implausíveis as duas hipóteses mais correntes na literatura brasileira: a de que no Brasil não há discriminação racial e a de que as pessoas de sangue misto têm posição privilegiada na sociedade, gozando de maiores oportunidades de vida e de mobilidade social. Isso ocorre porque, de acordo com ele, não só existe um resíduo substancial do passado escravocrata, que gera diferenças inter-raciais no campo econômico, mas também os contrastes entre pretos e pardos não são significativos, o que indica a existência de uma linha de cor entre brancos e não brancos.

Valle Silva assinala que,

3I HASENBALG, Carlos. Discriminação e desigualdades raciais no Brasil. Belo Horizonte: Editora UFMG; Rio de Janeiro: Iuperj, 2005.

32 VALLE SILVA, Nelson do, op. cit. 
No conjunto, esses resultados apontam para a existência de múltiplas desvantagens para os não brancos: eles são menos eficientes que os brancos na conversão de investimentos escolares em posições ocupacionais melhor remuneradas e no mercado de trabalho sofrem chances menores de ter uma carreira e mobilidade, cujo resultado são recompensas econômicas menores. As vantagens obtidas numa geração não são tão bem convertidas em vantagens para o novo coorte de filhos quanto entre os brancos ${ }^{33}$.

Os estudos realizados por Carlos Hasenbalg e Nelson do Valle Silva mostraram que a discriminação racial não se extinguiu com o fim da escravidão. Ao contrário, ela atualmente serve como um meio de direcionar aos brancos a quase exclusividade dos recursos e das posições sociais mais valorizadas. Com isso, a persistência da discriminação racial faz com que a mobilidade social dos negros fique prejudicada, mantendo-os, em grande número, nas camadas mais baixas da sociedade.

Essas pesquisas, junto com a emergência de diversos Conselhos de Desenvolvimento e Participação da Comunidade Negra, o reconhecimento oficial pelo governo federal, em I995, da existência da discriminação racial e do racismo, e a implantação do Grupo de Trabalho Interministerial (GTI) com a função de estimular e formular políticas de valorização da população negra, redundaram, como nos mostra Silvério34, em uma mudança de postura significativa, em todos os segmentos da sociedade brasileira, em relação ao tratamento das questões da população negra no país.

Silvério aponta a emergência do debate sobre a adoção de ações afirmativas (com as cotas assumindo o protagonismo dentre as diversas modalidades desse tipo de política pública) e registra que a discussão gira, aparentemente, em torno das mudanças ocorridas no pensamento social a partir do final da Segunda Guerra Mundial e suas implicações para a ação coletiva e para a ação estatal nos Estados Unidos. Esse fato nos permite aprender com a discussão sobre a ação afirmativa (affirmative action) e a identificação de distorções sociais ao considerar o credo americano e a realidade sobre a qual foram e são aplicadas aquelas políticas públicas e, também, suas repercussões no contexto brasileiro ${ }^{35}$.

Voltando à realidade brasileira e tomando como ponto de partida a persistência da precarização da população negra, alguns autores questionam a efetividade de adoção de políticas universalistas como meio de promover a ascensão social da população negra. Por isso, defendem que o poder público e os entes privados lancem mão de políticas de ação afirmativa que levem em conta o pertencimento racial, concomitantemente com a melhoria dos serviços públicos que garantam o pleno usufruto dos direitos sociais.

De acordo com Guimarães ${ }^{36}$, por mais universais e amplas que as políticas públicas sejam, existem certos setores da sociedade que, mesmo se baseando na

33 Ibidem, p. 98.

34 SILVÉRIO, Valter Roberto. Ação afirmativa e o combate ao racismo institucional no Brasil. Cadernos de pesquisa, n. $\amalg 17$, 2002, p. 2I9-246.

35 Ibidem.

36 GUIMARÃES, A. S. A. Racismo e antirracismo no Brasil. São Paulo: Ed. 34, I999. 
ideia de mérito, não são imunes às práticas de discriminação racial. Esses espaços onde as políticas universalistas têm pouco efeito prático só poderão ser acessíveis a representantes de grupos discriminados por meio de políticas afirmativas, que favoreçam o ingresso dessas pessoas nesses círculos.

Sendo assim, Guimarães conclui que não devemos dispensar o mesmo tratamento aos que são tratados como pertencentes a um grupo inferior, como no caso dos negros na sociedade brasileira, vítimas da discriminação racial. Nesse contexto, a adoção de políticas afirmativas tem, para ele, compromisso com o ideal de igualdade, o que justifica a necessidade de tratar, em certas situações, os "desprivilegiados" como privilegiados, como no caso dos negros, que sofreram e sofrem com a discriminação racial.

Os estudos elaborados na vigência do Projeto Unesco, as pesquisas surgidas no âmbito da Escola Paulista de Sociologia e os trabalhos produzidos por Carlos Hasenbalg e Nelson do Valle Silva mostraram a persistência da discriminação racial mesmo quase I30 anos após a abolição da escravatura.

Esses trabalhos, juntamente com a experiência estadunidense de combate à discriminação racial, redundaram em uma nova agenda, adotada pelos movimentos negros, que inclui a defesa da adoção de ações afirmativas pelos diversos setores da sociedade brasileira para promover a inclusão plena de negros.

Os estudos sobre as relações raciais no Brasil não tiveram conclusão unânime sobre o papel da discriminação racial na precarização da população negra. Outros estudos enfatizam que é a classe social, e não a raça, o principal fator dessa precarização. Para defender suas teses, os autores desses estudos se apoiam principalmente na visão de que há no Brasil uma relação mais pacífica entre negros e brancos e alto grau de mestiçagem da sua população.

\section{Classe, e não raÇa, COMO Principal fator de PRECARIZAÇÃo DA POPULAÇÃo NEGRA}

\section{Donald Pierson e Gilberto Freyre}

O sociólogo americano Robert Park ${ }^{37}$ afirma, na introdução do livro de outro sociólogo americano, Donald Pierson, intitulado Brancos e pretos na Bahia, que uma peculiaridade das relações raciais brasileiras é que o Brasil é um país onde não existe problema racial. $\mathrm{O}$ autor chega a essa conclusão por acreditar que no país qualquer pessoa negra ou mestiça que se revele capaz recebe sem dificuldades o lugar para o qual suas capacidades o habilitam, ou seja, há uma tendência no Brasil de absorver as pessoas de cor.

37 PARK, Robert E. Introdução à primeira edição norte-americana. In: PIERSON, Donald. Brancos e pretos na Bahia (estudo de contato racial). São Paulo: Companhia Editora Nacional, I971, p. 79-86. 
Donald Pierson ${ }^{38}$ diz que a ascensão das pessoas de cor no Brasil pode ocorrer principalmente em virtude de sua competência pessoal profissional, por sua ligação com uma família de prestígio ou por meio de algum tipo de ligação com pessoas brancas, seja por laço de parentesco, de apadrinhamento ou outros.

$\mathrm{O}$ autor acrescenta que essa ascensão pode ocorrer também em razão do grau de instrução, pela quantidade de recursos financeiros, por circunstâncias casuais ou exclusivamente pelo esforço dos indivíduos, um por um, e não como grupo, de modo que os conflitos com base na cor ou na classe sejam relativamente reduzidos.

Por isso, o que se encontra na Bahia, segundo Pierson ${ }^{39}$ (e que de certo modo ele estende à sociedade brasileira como um todo), é uma sociedade multirracial de classes, não existindo uma casta baseada em raças separadas, mas somente classes. Ele pondera que, mesmo que essas classes sejam identificadas com a cor, ainda assim elas devem ser vistas como classes.

Apesar de admitir a ocorrência de casos de discriminação racial, Pierson ${ }^{40}$ argumenta que eles não acontecem somente por causa da cor e, quando ocorrem, é porque, na maior parte deles, a cor é um dos critérios de posição social. $\mathrm{O}$ autor acrescenta que, quando existentes, os casos de discriminação racial não têm apoio da opinião pública e são alvos de reprovação geral e severa, tanto na imprensa como em outros setores da sociedade.

O sociólogo Gilberto Freyre ${ }^{4 \mathrm{~T}}$, no seu estudo clássico Casa grande e senzala: formação da família brasileira sob o regime da economia patriarcal, destaca que a sociedade brasileira foi formada tendo a agricultura como base econômica, o escravo negro como principal meio de mão de obra, e a mestiçagem e a hibridez como base da sua composição populacional.

Nesse contexto, a sociedade brasileira tem sido, de acordo com Freyre ${ }^{42}$, um equilíbrio de antagonismos, predominando a oposição senhor-escravo. $\mathrm{O}$ autor destaca que a existência desses antagonismos não impediu a confraternização e a mobilidade social no Brasil e, em alguns casos, até mesmo amorteceu os choques ou harmonizou essas contradições.

Em outro estudo, intitulado Sobrados e mucambos: decadência do patriarcado rural e desenvolvimento do urbano, Gilberto Freyre ${ }^{43}$ aponta que a disparidade entre os diversos grupos sociais no Brasil é originária do conflito entre as diversas fases ou momentos da cultura. No início, essa desigualdade se relacionava às três raças (negros, brancos e indígenas), mas na atualidade refere-se unicamente a populações

38 PIERSON, Donald. Brancos e pretos na Bahia. In: . Brancos e pretos na Bahia (estudo de contato racial).

São Paulo: Companhia Editora Nacional, I97I, p. 345-37I.

39 Ibidem.

40 Ibidem.

4I FREYRE, Gilberto. Casa grande e senzala: formação da família brasileira sob o regime da economia patriarcal.

São Paulo: Global, 2006.

42 Ibidem.

43 Idem, Sobrados e mucambos: decadência do patriarcado rural e desenvolvimento do urbano. Rio de Janeiro/ São Paulo: Record, 2000. 
puramente sociais, a diferenças regionais e à maior ou menor facilidade de contatos sociais e intelectuais.

Além disso, essa disparidade se origina, segundo Freyre ${ }^{44}$, das distâncias sociais, que aumentaram ao fim da era colonial. Ele diz que o agravamento das disparidades sociais foi provocado pelo desenvolvimento da economia industrial, em certas regiões, em beneficio de minorias econômica e politicamente poderosas. $\mathrm{O}$ autor afirma que essas diferenças nas condições materiais de vida vieram a coincidir, em consequência da escravidão, com a diversidade de cor ou raça.

A expressão que resume todos esses estudos é a de que no Brasil não existe problema racial. Nesses trabalhos, o Brasil se configura em uma sociedade multirracial de classes, onde a cor não é o principal critério que favoreça ou dificulte a mobilidade social. A competência individual, o nível educacional, as relações de apadrinhamento ou de compadrio são fatores mais importantes que a cor no processo de mobilidade ascendente ou descendente.

De acordo com essas pesquisas, a desigualdade racial existente no Brasil seria resultado das distâncias sociais originadas pela ordem escravocrata e das diferenças sociais entre a classe explorada e a exploradora e não de diferenças raciais.

É a partir desses estudos, especialmente aqueles elaborados por Gilberto Freyre ${ }^{45}$, que emerge e se consolida na sociedade brasileira a ideia de que o Brasil seria uma democracia racial. De acordo com essa ideologia, o Brasil seria um país livre de discriminação racial, onde negros e brancos conviveriam pacificamente e todos teriam as mesmas oportunidades de ascensão social.

Os trabalhos sobre relações raciais elaborados pelo Projeto Unesco que tiveram como campo de pesquisa a Região Nordeste chegaram a conclusões semelhantes às dos trabalhos produzidos por Donald Pierson e Gilberto Freyre, a saber: a cor e o pertencimento racial não seriam necessariamente obstáculos à convivência e à ascensão social dos negros no Brasil. Ou seja, para esses autores, diferentemente de outros lugares, como os Estados Unidos, por exemplo, negros e brancos compartilhavam, de modo geral, oportunidades iguais na sociedade brasileira.

\section{Estudos sobre relações raciais patrocinados pela Unesco (Região Nordeste)}

Os trabalhos de pesquisa sobre relações raciais no Brasil financiados pela Unesco destacados neste tópico se concentraram na Região Nordeste, que ainda não tinha passado pelo processo de industrialização pelo qual passavam as cidades do Rio de Janeiro e de São Paulo.

Ao pesquisar a cidade de Minas Velhas, no interior da Bahia, o antropólogo americano Marvin Harris ${ }^{46}$ detectou, no seu livro Town and country in Brazil, que o comportamento do branco em direção ao negro difere do ideal que deveria ser.

Em sua pesquisa, o autor cita alguns exemplos, que o levam à conclusão de

44 Ibidem.

45 Ibidem.

46 HARRIS, Marvin. Class and race. In: . Town and country in Brazil. New York: Columbia University Press,

I956, p. 96-I46 (tradução nossa). 
que há uma contradição entre o ideal baseado em um pensamento estereotipado sobre o negro e o comportamento efetivamente realizado, que contradizia juízos preconceituosos sobre o negro.

Isso ocorria porque a principal razão para a diferença entre as ideias preconcebidas e o comportamento real é que os termos negro e branco indicam um recorte que não é identificado por ninguém. $\mathrm{O}$ autor destaca que no dia a dia o conjunto de características físicas por si mesmo não determina o papel do indivíduo na sociedade ${ }^{47}$.

Levando em conta essa constatação, Harris conclui que:

Não há um status, um papel para o negro como um negro nem para o branco como um branco, exceto dentro da cultura ideal. Raça é, todavia, um dos vários critérios que determinarão como as massas de outros indivíduos na verdade se comportarão em direção a ele. Em outras palavras, riqueza, ocupação e educação [...] têm até certo ponto o poder de definir raça. Isso se deve ao fato de que não existem grupos socialmente importantes em Minas Velhas que sejam determinados puramente por características físicas ${ }^{48}$.

Já o sociólogo Thales de Azevedo 49 , que pesquisou a sociedade baiana no seu livro As elites de cor: um estudo de ascensão social, destaca que, embora o pertencimento a certa classe social determine, dentre outros termos, o status dessas pessoas, a ascensão social se processa por livre competição, de tal modo que pretos e mestiços, como indivíduos, podem, por meio do seu mérito ou de circunstâncias favoráveis, melhorar de condição social e mesmo conseguir uma posição nas camadas superiores da sociedade baiana, sendo que essa posição será relativa não somente ao grupo de cor a que pertence, mas à comunidade em geral.

Porém, o autor pondera que, mesmo que a cor represente a experiência passada da escravidão e seja invocada por muitos como explicação para a dificuldade de ascensão social das pessoas com traços fenotípicos negros mais acentuados, esse fato não as impede, nem mesmo as mais claras e de traços fenotípicos brancos, de adquirir status tão elevado quanto o dos brancos.

Em trabalho posterior, Thales de Azevedo ${ }^{50}$ muda a sua estratégia de análise da sociedade baiana ao destacar que o retardamento da industrialização era um dos fatores para a permanência dessa situação de conservadorismo social e de maior acúmulo de pessoas negras nas classes mais baixas da sociedade. Por isso o autor previa que, se na sociedade baiana persistissem os valores culturais que se opõem, em medida variável, à discriminação racial, seria possível que uma mudança na

47 Ibidem (tradução nossa).

48 Ibidem, p. I26 (tradução nossa).

49 AZEVEDO, Thales. Uma sociedade multirracial de classes. In: . As elites de cor: um estudo de ascensão social. São Paulo: Companhia Editora Nacional, I955, p. 70-78.

50 Idem. Classes sociais e grupos de prestígio. In: . Cultura e situação racial no Brasil. Rio de Janeiro:

Civilização Brasileira, I956, p. 30-43. 
estrutura econômica criasse condições para a ascensão social de grande número de pessoas das classes mais baixas.

Por outro lado, ele afirma que a ascensão social das pessoas negras, principalmente daquelas com traços fenotípicos mais característicos desse grupo de cor, poderia levar a uma modificação dos valores que condenam a discriminação racial. A consequência dessa mudança poderia justificar a formação de um novo regime de castas, como o que ocorria nos Estados Unidos, com sistemas de classes sociais autônomas brancas e não brancas ${ }^{51}$.

Os estudos da Unesco que se concentraram na Região Nordeste chegaram a conclusões diferentes dos estudos que se detiveram na análise das relações raciais na Região Sudeste.

Esses estudos concluíram que as diferenças de cor não determinam o papel do indivíduo na sociedade, ou seja, o fato de uma pessoa ser negra ou branca não significa que ela não possa ter um status social semelhante ao dos brancos. A mobilidade social de um indivíduo estaria, assim, ligada a outros fatores que não somente a sua cor.

Nos dias atuais, alguns estudos sobre relações raciais no Brasil procuram reelaborar a ideia de democracia racial, redefinindo-a como um parâmetro organizador das relações sociais entre negros e brancos no Brasil, ao invés de uma ideologia forjada pelas elites para mascarar o racismo. Para os seus autores, essa ideologia teria o poder de influenciar positivamente a convivência entre os grupos raciais brasileiros.

Além disso, a maior parte dos autores desses estudos tem se colocado contra a adoção de políticas de ações afirmativas de cunho racial, pois defendem que essas políticas poderiam, ao invés de diminuir, acirrar a discriminação racial na sociedade brasileira, gerando um efeito contrário daquele que elas procuram atingir.

\section{A ideia de democracia racial como parâmetro para as relações raciais no Brasil}

A ideia de democracia racial, definida por Florestan Fernandes ${ }^{52}$ como mito e como falsa consciência da realidade das relações raciais no Brasil, foi reelaborada por alguns antropólogos, deixando de ter o caráter descrito por Fernandes e passando a ser vista como um discurso fundador da sociedade brasileira.

No livro Cultura brasileira eridentidade nacional, o sociólogo Renato Ortiz ${ }^{53}$ destaca que na virada do século XIX para o século XX surge a fábula ou o mito das três raças, que sugere a existência de um ponto de partida a partir do qual se irradia uma história mítica. Esse ponto de partida seria a ideia de um Brasil cadinho, onde as três raças se fundiram nas selvas brasileiras.

Ortiz ${ }^{54}$ ainda aponta que esse mito surge quando a sociedade passa por

5 I Ibidem.

52 FERNANDES, Florestan, I965, op. cit.

53 ORTIZ, Renato. Da raça à cultura: a mestiçagem e o nacional. In: . Cultura brasileira eridentidade

nacional. São Paulo: Brasiliense, I985, p. 37-44.

54 Ibidem. 
transformações profundas, deixando de ser uma sociedade escravista e monárquica para se tornar uma sociedade capitalista e republicana.

Complementando essa ideia no livro Negritude sem etnicidade, o antropólogo italiano Lívio Sansone 55 diz que,

Se a democracia racial é um mito - como sem dúvida é-, estamos lidando com um mito fundador das relações sociorraciais brasileiras, cujas origens se inspiram na fábula da mistura mágica de três raças: branco, negro e índio. Esse mito é aceito por uma grande parte da sociedade, que o reproduz nas relações cotidianas, articulando-o numa série de discursos populares. Nesses discursos [...] a democracia racial, em vez de ser uma situação concreta da sociedade contemporânea, é transformada num valor, no sonho com uma sociedade melhor, mais justa e menos discriminatória, na qual todos sejam gente ${ }^{56}$.

Dentro dessa nova abordagem sobre o mito da democracia racial, e pontuando que as representações sociais não são menos reais que as relações raciais, ocorrendo na verdade o contrário, o antropólogo Peter Fry ${ }^{57}$ destaca, no seu livro A persistência da raça: ensaios antropológicos sobre o Brasil e a África austral, que a ideia de democracia real é tão real quanto a discriminação racial.

Para Fry, ao mesmo tempo que essa ideia de democracia produziu uma sociedade sem segregação racial e legalmente universalista, a discriminação racial só é possível porque, antes dela, há outra ideologia que contesta a ideia de democracia racial e que hierarquiza as pessoas de acordo com a sua aparência.

A partir daí, o autor contesta a ideia de que a democracia racial é um mito, como algo que não existe na realidade. Para ele, quando se aborda o mito da democracia racial em uma perspectiva mais antropológica, como padrão de ação social ou um sistema ordenado de pensamento social que expressa entendimentos fundamentais a respeito da sociedade, pode-se compreendê-lo não como impedimento à consciência social, mas como fundamento do significado que a ideia de raça assume para a maioria dos brasileiros.

Apoiando-se nessa concepção antropológica do mito da democracia racial e na influência que essa ideia trouxe às relações raciais no Brasil, Fry ${ }^{58}$ teme que as políticas diferenciadas, que levam em conta a cor em sua aplicação, como as ações afirmativas e as cotas para negros, ao imaginarem um Brasil de raças e grupos étnicos estanques, venham consequentemente a criar o que não existe.

Ao comentar sobre as políticas de ação afirmativa que levam em conta a cor, mais especificamente a política de cotas raciais, em artigo escrito para a revista Estudos

55 SANSONE, Livio. Negritude sem etnicidade. Salvador: Editora da UFBA, 2003.

56 Ibidem, p. 82-83.

57 FRY, Peter. A persistência da raça: ensaios antropológicos sobre o Brasil e a África austral. Rio de Janeiro:

Civilização Brasileira, 2005.

58 Ibidem. 
avançados, Yvonne Maggie e Peter Fry ${ }^{59}$ colocam em dúvida a pertinência desse tipo de política no Brasil.

Em primeiro lugar, esses autores, que representam essa corrente de pensamento, defendem que esse tipo de política pode incentivar animosidades raciais porque acreditam que não se pode vencer o racismo celebrando o conceito de raça, visto que o racismo, em tese, não existiria se o próprio conceito de raça não existisse. Em segundo lugar, eles não estão convencidos de que a solução universalista foi de fato esgotada. Em terceiro lugar, acreditam que, no lugar de políticas de cotas e de ações afirmativas com recorte racial, deveria se apostar em políticas dirigidas às regiões mais pobres, que atingiriam automaticamente os negros, porque os pobres majoritariamente são negros ${ }^{60}$.

Ao contrário do que fez Florestan Fernandes ao considerar a democracia racial como mito, como algo que carece de verdade, esses estudos a reabilitaram. Essa corrente de pensamento fez com que ela se transformasse na ideia que organizaria e influenciaria as relações sociais entre negros e brancos no Brasil. A democracia racial seria, para esses autores, responsável por uma relação de maior proximidade entre os diversos grupos raciais e pela condenação da discriminação por grande parte da sociedade brasileira.

\section{Algumas CONSIDERAÇÕES SOBRE OS ESTUdOS DE RELAÇÕES RACIAIS NO BRASIL}

A apresentação desses dois grupos de argumentos teve como objetivo resgatar as conclusões das pesquisas sociológicas e antropológicas que abordaram a precarização da população negra na sociedade brasileira. Optou-se por esse tipo de estruturação do artigo porque, apesar de os autores não se manterem neutros nesse debate e aceitarem os argumentos que favorecem as políticas afirmativas, a definição dos termos do debate sobre as relações raciais no Brasil possibilita ao leitor o contato com os diversos argumentos e reflexões de vários autores.

Em ambos os paradigmas, houve mudança de perspectiva sobre as relações entre negros e brancos no Brasil.

No grupo de autores que acreditam que a discriminação racial no Brasil é um dos fatores principais para a precarização da população negra na sociedade brasileira, abandonou-se a crença de que a industrialização acabaria com a discriminação racial porque ela seria uma persistência do passado, uma herança da escravidão. O que se viu, a partir dos trabalhos de Carlos Hasenbalg e Nelson do Valle Silva ${ }^{6 I}$, é que a

59 MAGGIE, Yvonne; FRY, Peter. A reserva de vagas para negros nas universidades brasileiras. Estudos avançados, v. I8, n. 50, 2004, p. 67-80.

60 O desfecho final da discussão da ADPF, por parte do Superior Tribunal Federal - STF, mostrou que o país não estava preparado para adotar as cotas raciais, por isso tivemos que nos contentar com as cotas sociais, que incluem negros, índios e pobres.

6I VALLE SILVA, Nelson do, op. cit. 
industrialização não acabou com o preconceito racial, tendo este assumido novas formas que objetivavam a manutenção da hierarquização social.

Houve também mudança de perspectiva no paradigma daqueles que acreditam que a precarização da população negra na sociedade brasileira é uma questão de classe, e não de raça: enquanto os primeiros autores acreditavam que o Brasil era uma democracia racial de fato e que a discriminação contra o negro era resíduo do passado escravocrata, os atuais não negam a existência de discriminação contra os negros, mas ainda acreditam que a pobreza é o principal obstáculo para a sua ascensão social.

Outra mudança vista nesse grupo é em relação à ideia de democracia racial: de falsa consciência da realidade, passou a ser vista como um organizador das relações entre negros e brancos no Brasil. Apesar de aceitarem o fato de que essa ideia não se sustenta na realidade, esses autores acreditam que a democracia racial deve ser vista da seguinte maneira: como uma ideia que condena manifestações brutais de discriminação racial e que corresponde a um desejo da maior parte da sociedade brasileira de que a cor não seja motivo para o tratamento desigual entre as pessoas.

Para além das discussões filosóficas, sociológicas e antropológicas, mas levando em consideração as diversas posições teóricas, coube ao direito constitucional estabelecer a linha de interpretação que, se não põe fim ao debate intelectual, pelo menos passa a balizar o exercício do direito, as decisões do sistema de justiça e a postura das instituições de ensino de todos os níveis e modalidades.

Decidindo por unanimidade pela constitucionalidade do sistema de cotas nas instituições de ensino no Brasil, questionada pelo Partido Democratas (DEM) por meio da Arguição de Descumprimento de Preceito Fundamental (ADPF) n. I86, o Supremo Tribunal Federal ${ }^{62}$, em 26 de abril de 20I2, decidiu a questão no plano jurídico e, por isso mesmo, os principais argumentos utilizados por nove de seus ministros ${ }^{63}$ são aqui transcritos, à guisa de conclusão deste artigo. As citações a seguir foram retiradas do acórdão relativo ao julgamento da ADPF n. I86, que decidiu pela adequação da política de cotas aos princípios constitucionais. Vale a pena ressaltar que os votos se apoiaram principalmente nos três principais argumentos utilizados pelos defensores da política de cotas: como instrumento de reparação pela escravidão e discriminação racial, como promotora de justiça social e igualdade material e como promotora de espaços mais plurais e diversos.

62 BRASIL. Supremo Tribunal Federal. Inteiro Teor do Acórdão da Arguição de Descumprimento de Preceito Fundamental (ADPF) n. I86. Brasília, 26 de abril de 20I2, 233 p.

63 A composição do STF é de onze ministros, mas o ministro Dias Toffoli foi impedido de participar do julgamento, pois, quando exercia a função de advogado-geral da União, posicionou-se a favor da reserva de vagas. Além disso, o ministro César de Mello abriu mão de se pronunciar. 
[...] eu me sinto muito confortável para analisar a questão das ações afirmativas, inclusive como aplicação do princípio da igualdade. [...] a própria realização do princípio de igualdade em muitos casos exige uma ação, seja do legislador, seja da administração, seja de algum setor no sentido de realizar essa equiparação. [...] Por que o legislador faz esse tipo de opção? Certamente a partir de algum tipo de referência com base na própria realidade [ministro Gilmar Mendes] ${ }^{64}$.

[...] a Constituição Brasileira de I988 produziu, a meu ver, uma grande diferença em relação aos outros textos constitucionais, porque não apenas reforçou [...] o princípio da igualdade formal, mas por partir da compreensão de que a igualdade é processo dinâmico, por isso a igualação, porque a igualdade é estática, é garantia daquele que já se igualou. E a igualação é um processo dinâmico de fazer com que aqueles que não adquiriram ainda uma condição de poder ter igualdade de oportunidades para ser igualmente livres possam vir a adquirir essas condições, daí as políticas chamadas de compensatórias [ministra Cármen Lúcia] ${ }^{65}$.

A Constituição [...] não se contentou com proibir o preconceito. Foi muito além. A Constituição entendeu que uma política punitiva, repressiva, sancionatória, vedatória do racismo era necessária, mas não suficiente. Era preciso promover os nossos irmãos negros que historicamente acumularam desvantagens, perseguições humilhantes e ignominiosas [ministro Ayres Brito ${ }^{66}$.

A questão do mérito pessoal [...] ignora a força dos obstáculos. Historicamente opostos aos esforços dos grupos marginalizados e cuja superação não depende das vítimas da marginalização, senão de terceiros. [...] O mérito é, sim, um critério justo ou o mais justo, mas, no caso, é justo apenas em relação aos candidatos que tiveram oportunidades idênticas ou, pelo menos, assemelhadas de preparação. Não é possível, então, usar esse mesmo critério também para aqueles que no seu passado não tiveram iguais condições objetivas de suportar agora julgamento por esse critério a título de justiça [ministro Cezar Peluso] ${ }^{67}$.

Pode-se dizer, sem receio de equívoco, que se passou de uma igualização estática, meramente negativa, no que se proibia a discriminação, para uma igualização eficaz, dinâmica, já que os verbos "construir", "garantir", "erradicar" e "promover” implicam mudança de ótica ao denotar “ação”. Não basta não discriminar. É preciso viabilizar -e a Carta da República oferece base para fazê-lo - as mesmas oportunidades. Há de ter-se como página virada o sistema simplesmente principiológico. A postura deve ser, acima de tudo, afirmativa [ministro Marco Aurélio Mello] ${ }^{68}$.

\footnotetext{
64 BRASIL, 20I2, op. cit., p. I63.

65 Ibidem, p. I32.

66 Ibidem, p. 228.

67 Ibidem, p. I62.

68 Ibidem, p. 2I3.
} 
A discriminação e o preconceito existentes na sociedade não têm origem em supostas diferenças no genótipo humano. Baseiam-se, ao revés, em elementos fenotípicos de indivíduos e grupos sociais. São esses traços objetivamente identificáveis que informam e alimentam as práticas insidiosas de hierarquização racial ainda existentes no Brasil. Nesse cenário, o critério adotado pela UnB busca simplesmente incluir aqueles que, pelo seu fenótipo, acabam marginalizados. Diante disso, não vislumbro qualquer inconstitucionalidade na utilização de caracteres físicos e visíveis para definição dos indivíduos afrodescendentes [ministro Luiz Fux ${ }^{69}$.

Mas, por ser uma igualdade formal, com idêntico tratamento em normas gerais e abstratas, trata-se de igualdade presumida, enquanto desconsidera processos sociais concretos de formação de desigualdades. Identificadas essas desigualdades concretas, a presunção de igualdade deixa de ser benéfica e passa a ser um fardo, fardo porque impede que se percebam as necessidades concretas de grupos que, por não terem as mesmas oportunidades, ficam impossibilitados de galgar os mesmos espaços daqueles que desfrutam de condições sociais mais favoráveis. E, sem igualdade mínima de oportunidades, não há igualdade de liberdade. Inegavelmente, as possibilidades de ação, de escolhas de vida, de visões de mundo, de chances econômicas, as manifestações individuais ou coletivas específicas são muito mais restritas para aqueles que, sob a presunção da igualdade, não têm consideradas as suas condições particulares. Necessária se faz, então, a intervenção do Estado, que tem ocorrido em especial por meio das chamadas ações afirmativas. É preciso adentrar no mundo das relações sociais e corrigir a desigualdade concreta para que a igualdade formal volte a ter seu papel benéfico [ministra Rosa Weber] ${ }^{70}$.

Como é de conhecimento geral, o reduzido número de negros e pardos que exercem cargos ou funções de relevo em nossa sociedade, seja na esfera pública, seja na privada, resulta da discriminação histórica que as sucessivas gerações de pessoas pertencentes a esses grupos têm sofrido, ainda que na maior parte das vezes de forma camuflada ou implícita. Os programas de ação afirmativa em sociedades em que isso ocorre, entre as quais a nossa, são uma forma de compensar essa discriminação, culturalmente arraigada, não raro, praticada de forma inconsciente e à sombra de um Estado complacente [ministro Ricardo Lewandowski] ${ }^{7 x}$.

Senhor presidente, eu, efetivamente, não tenho nada mais a acrescentar ao exaustivo e excelente voto do Ministro Lewandowski, que, a meu ver, esgotou completamente o tema. $\mathrm{O}$ voto de Sua Excelência não só é convincente, mas é abrangente e inteiramente em sintonia com o que há de mais moderno na literatura sobre o tema [ministro Joaquim Barbosa] $]^{72}$.

\footnotetext{
69 Ibidem, p. II9.

70 Ibidem, p. 225 .

7I Ibidem, p. 66-67.

72 Ibidem, p. 154
} 
A decisão do STF não põe fim ao racismo, ao preconceito e à discriminação, mas significa que, em termos de orientação das políticas públicas implementadas pelo Estado brasileiro, por suas instituições e seus agentes, inclusive a educação, a escola e o ensino da história, a determinação é no sentido de adotar as ações afirmativas como meio para buscar a desejada igualdade. Doravante, a pesquisa acadêmica deveria se ocupar de aferir se, a médio e longo prazos, essas ações afirmativas realmente contribuem para a superação das condições que historicamente colocaram o povo negro em situação de marginalização social e o que essa superação poderia significar em termos de consolidação de um país mais igualitário, mais justo e mais solidário.

\section{SOBRE OS AUTORES}

ROBERTO DA SILVA é professor livre-docente do Departamento de Administração Escolar e Economia da Educação da Faculdade de Educação da Universidade de São Paulo (FE/USP).

E-mail: kalil@usp.br

JULIANO DA SILVA TOBIAS é mestre em Educação pela Faculdade de Educação da Universidade de São Paulo e professor de Educação Infantil e Ensino Fundamental I da Prefeitura do Município de São Paulo. E-mail: julitobias@usp.br

\section{REFERÊNCIAS BIBLIOGRÁFICAS}

AZEVEDO, Thales. Classes sociais e grupos de prestígio. In: . Cultura e situação racial no Brasil. Rio de Janeiro: Civilização Brasileira, I956, p. 30-43.

.Uma sociedade multirracial de classes. In: . As elites de cor: um estudo de ascensão social. São Paulo: Companhia Editora Nacional, I955, p. 70-78.

BASTIDE, Roger; FERNANDES, Florestan. Brancos e negros em São Paulo: ensaio sociológico sobre aspectos da formação, manifestações atuais e efeitos do preconceito de cor na sociedade brasileira. São Paulo: Global, 2008.

BRASIL. Conselho Nacional de Educação. Resolução CNE/CP n. I, de I7 de junho de 2004. Institui Diretrizes Curriculares Nacionais para a Educação das Relações Étnico-Raciais e para o Ensino de História e Cultura Afro-Brasileira e Africana.

. Diretrizes curriculares nacionais para a educação das relações étnico-raciais e para o ensino de história e cultura afro-brasileira e africana. Brasília: Ministério da Educação - MEC, 2004.

. Supremo Tribunal Federal. Inteiro Teor do Acórdão da Arguição de Descumprimento de Preceito Fundamental (ADPF) n. I86. Brasília, 26 de abril de 20I2, 233 p. 
CARDOSO, Fernando Henrique. Capitalismo e escravidão no Brasil meridional: o negro na sociedade escravocrata do Rio Grande do Sul. Rio de Janeiro: Civilização Brasileira, 2003.

FERNANDES, Florestan. Heteronomia racial na sociedade de classes. In: A integração do negro na sociedade de classes. Volume I - O legado da raça branca. São Paulo: Companhia Editora Nacional, I965, p. 2II-26I.

. Cor e estrutura social em mudança. In: BASTIDE, Roger; FERNANDES, Florestan. Brancos e negros em São Paulo: ensaio sociológico sobre aspectos da formação, manifestações atuais e efeitos do preconceito de cor na sociedade brasileira. São Paulo: Global, 2008, p. 9I-I54.

FREYRE, Gilberto. Casa grande e senzala: formação da família brasileira sob o regime da economia patriarcal. São Paulo: Global, 2006.

. Sobrados e mucambos: decadência do patriarcado rural e desenvolvimento do urbano. Rio de Janeiro/São Paulo: Record, 2000.

FRY, Peter. A persistência da raça: ensaios antropológicos sobre o Brasil e a África austral. Rio de Janeiro: Civilização Brasileira, 2005.

GRAHAM, Richard. Brazilian slavery re-examined: a review article. Journal of social history, v. 3, n. 4, Summer, I970, p. 43I-453.

GUIMARÃES, A. S. A. Racismo e antirracismo no Brasil. São Paulo: Ed. 34, I999.

HARRIS, Marvin. Class and race. In: . Town and country in Brazil. New York: Columbia University Press, I956, p. 96-I46.

HASENBALG. Carlos. Discriminação e desigualdades raciais no Brasil. Belo Horizonte: Editora UFMG; Rio de Janeiro: Iuperj, 2005.

IANNI, Octavio. O negro e o mulato. In: . As metamorfoses do escravo: apogeu e crise da escravatura no Brasil Meridional. São Paulo: Difusão Europeia do Livro, I962, p. 236-268.

MAGGIE, Yvonne; FRY, Peter. A reserva de vagas para negros nas universidades brasileiras. Estudos avançados, v. I8, n. 50, 2004, p. 67-80.

MÈTRAUX, Alfred. Unesco and the racial problem. International Social Science Bulletin, v. II, n. 3, I950, p. 384.

NOGUEIRA, Oracy. Preconceito racial de marca e preconceito racial de origem (sugestão de um quadro de referência para a interpretação do material sobre relações raciais no Brasil). In: . Tanto preto quanto branco: estudos de relações raciais. São Paulo: T. A. Queiroz, I985, p. 67-93.

ORTIZ, Renato. Da raça à cultura: a mestiçagem e o nacional. In: . Cultura brasileira eridentidade nacional. São Paulo: Brasiliense, I985, p. 37-44.

PARK, Robert E. Introdução à primeira edição norte-americana. In: PIERSON, Donald. Brancos e pretos na Bahia (estudo de contato racial). São Paulo: Companhia Editora Nacional, I97I, p. 79-86.

PIERSON, Donald. Brancos e pretos na Bahia. In: . Brancos e pretos na Bahia (estudo de contato racial). São Paulo: Companhia Editora Nacional, I97I, p. 345-37I.

PINTO, Luis Aguiar Costa. O negro no Rio de Janeiro: relações de raças numa sociedade em mudança. São Paulo: Companhia Editora Nacional, I953.

SANSONE, Lívio. Negritude sem etnicidade. Salvador: Editora da UFBA, 2003.

SILVÉRIO, Valter Roberto. Ação afirmativa e o combate ao racismo institucional no Brasil. Cadernos de pesquisa, n. II7, 2002, p. 2I9-246.

SKIDMORE, Thomas E. Preto no branco: raça e nacionalidade no pensamento brasileiro. Rio de Janeiro: Paz e Terra, I989.

VALLE SILVA, Nelson do. Diferenças raciais de rendimentos. In: HASENBALG, Carlos; VALLE SILVA, Nelson do; LIMA, Márcia. Cor e estratificação social. Rio de Janeiro: Contra Capa, I999, p. I84-2I6. 